\title{
Tibet, Nationalism, and the "West": Questioning Economic and Political Modernity
}

\section{Sebastian Veg}

\section{(2) OpenEdition \\ Journals}

Édition électronique

URL : http://journals.openedition.org/chinaperspectives/4859

DOI : 10.4000/chinaperspectives.4859

ISSN : 1996-4617

Éditeur

Centre d'étude français sur la Chine contemporaine

\section{Édition imprimée}

Date de publication : 1 septembre 2009

ISSN : 2070-3449

\section{Référence électronique}

Sebastian Veg, "Tibet, Nationalism, and the "West": Questioning Economic and Political Modernity ", China Perspectives [En ligne], 2009/3 | 2009, mis en ligne le 01 septembre 2012, consulté le 15 septembre 2020. URL : http://journals.openedition.org/chinaperspectives/4859 
U

\title{
Tibet, Nationalism,
}

\section{and Modernity}

Two Chinese Contributions ${ }^{(1)}$

\author{
SEBASTIAN VEG
}

$\tau$ n April 2008, one month after the Tibetan revolt of 14 March, the Tsinghua professor of intellectual history Wang Hui was interviewed by $T_{\text {wenty-first }}$ Century Economic Herald (Ershiyi shiji jingji baodao) about the events. He then reworked this interview into a full-fledged essay that was published in the Hainan journal Frontiers (Tianya $\left.{ }^{(2)}\right)$. This article promised to yield some interesting insights as to the "misunderstanding" that had developed between China and what part of the Chinese press and the government referred to as "the West": Wang Hui is probably more well-read in Englishlanguage publications dealing with China, as well as with general problems of modern politics and culture, than most Western sinologists could claim to be in Chinese. He is well known for taking iconoclastic positions, critical both of the government and of the assumptions made by some of its critics; in particular, he has repeatedly taken the Chinese leadership to task over its embrace of unfettered capitalism, arguing that the political repression it exercises has in the last 20 years been increasingly subordinated to a policy of crony capitalism rather than to ideology, and that liberalism alone will therefore not solve China's present problems.

In May 2009, a research report prepared by four researchers (Fang Kun, Huang Li, Li Xiang, Wang Hongzhe) for the Gongmeng Law Research Center appeared on the internet, entitled "Investigation of the Social and Economic Causes of the 14 March Incident in Tibetan Areas," which represents the most thorough field inquiry to date into how the revolts of 2008 were experienced and understood by local populations in Tibetan areas. ${ }^{(3)}$ Prepared by a non-governmental organisation run by several prominent lawyers and law professors active in the rights defence movement (weiquan yundong), which has since been shut down on tax charges by the Beijing authorities, who have also formally arrested its director $\mathrm{Xu}$ Zhiyong, ${ }^{(4)}$ this report drew much attention. Its opening statement describes the revolts in the following way:

Such a large social contradiction could not have been created solely by external factors. There must be internal causes, but media reports have given little

detailed consideration to investigating the social roots of these violent incidents. Under the influence of nationalist sentiment, there were some reports that even broadened mistrust and mutual criticism between the nationalities. The lack of field research into the living conditions of Tibetans has been detrimental to clearly understanding the nature of the social contradictions in Tibetan areas on a theoretical level, and has been detrimental to resolving problems on a practical level. (Foreword)

In addition to religious and ethnic discontent, the authors mention the "rise of China" and its influence on Tibet as factors in the protests, pinpointing the fact that "this hurried process of modernization and the path it has taken are not the result of choices made by Tibetans of their own volition; there were very many powerful external forces at play" (I, introduction).

1. The author would like to thank William Nee and Françoise Robin for commenting on the paper; and Wang Hui for providing the revised version of his article.

2. Wang Hui, "Dongfang zhuyi, minzu quyu zizhi yu zunyan zhengzhi - guanyu 'Xizang wenti' de yidian sikao" (Orientalism, Self-rule of ethnic areas, and the politics of dignity-a few thoughts about the 'Tibet problem,'” Tianya (Frontiers), 2008, no. 4 (July 2008), pp. 173-191. Page numbers in parentheses refer to this article; when they are preceded by "revised," they refer to the unpublished manuscript ("Dong Xi Zhijian de 'Xizang wenti'; The "Tibetan problem" between East and West; 53pp) provided by the author and to be published by Kaifang Shidai (Open Times). Since the Tianyi website (www.tecn.cn) was shut down in early July 2009 , only a slightly expanded version is available online via the Utopia website: http://www.wyzxsx.com/Article/Class17/ 200807/44904.html. The original interview with Economic Herald, which appeared on 28 April, is also available at: http://www.wyzxsx.com/Article/Class17/200806/ 40777.html (All websites last accessed on 13 August 2009).

3. Gongmeng (Open Constitution Initiative) Law Research Center, Zangqu 3.14 shijian shehui jingji chengyin diaocha baogao (Investigation of the Social and Economic Causes of the 14 March Incident in Tibetan areas), https://docs.google.com/Doc?id=df4nrxxq 91ctcf6sck. The version on Woeser's blog also contains Appendix I, missing on the Google site: http://woeser.middle-way.net/2009/05/314.html. An English translation was prepared by the International Campaign for Tibet, but is marred by several elementary translations errors (such as "ethnic state" for minzu guojia, rather than "nation-state"; the first author is given as Li Kun rather than Fang Kun, etc.); it is available at www.savetibet.org/print/2197. Quotations from the report are followed by the reference in the internal structure of the report, as there are no stable page numbers). Research for the report was carried out in Tibetan areas in the TAR and Amdo (Qinghai and Gansu province); unfortunately it seems the researchers did not (could not?) visit Kham.

4. For example, Reuters, "Gongmeng rights lawyer arrested," South China Morning Post 19 August 2009, p. A6. 
The receipt for confiscated documents provided to Gongmeng by the Beijing Civil Affairs Administration. The Tibet Report is listed on lines 2 and 6.

(C) Boxun

Wang Hui reworked and considerably expanded his original paper after the publication of this report, which he quotes several times, and it is tempting to think that it influenced his thinking more than appears on the surface. Indeed, on several important points, Wang Hui's reworked paper considerably inflects his original position in keeping with findings by the Gongmeng Initiative, in particular on the importance of the religious dimension of Tibetan society; on the unique nature of inequalities in Tibetan areas, in that they espouse ethnic fracture lines; and on the feeling of disempowerment of Tibetans due to the massive influx of migrants, in particular to the Tibet Autonomous Region (TAR), which he earlier likened to "the problem of migrants in any major Chinese city"-in the revised version this is designated as the "main spark" of the March riots. The closeness in vocabulary is particularly striking in the following passage of the introduction, which in the earlier version chided only Western public opinion:

Western public opinion immediately focused on Lhasa, the Dalai Lama and the exiled Tibetan clique, while Chinese official media began attacking Western public opinion; both focused on the violence and the action of the overseas Tibetan independence movement, and very rarely discussed the reasons for the 14 March events from the viewpoint of a social crisis. [...] Even more importantly: why do both of the reactions described above focus on nationalism, and not on the social conditions that produced the Tibetan crisis? (Revised version, p. 1)

Despite these important additions, the conceptual framework remains generally unchanged, as Wang Hui uses key notions developed in other essays to shed light on the contradictions of Tibet, in particular his critique of the empire/nation-state dichotomy developed in the four-volume The Rise of Modern Chinese Thought, and his views on "depoliticised politics" inspired by Carl Schmitt (see below notes 8 and 18). The present paper therefore refers to both the article originally published in Tianya and the expanded version kindly provided by the author-especially as the former was widely circulated on the Internet, while the latter has yet to be published. While in the earlier version there is a strong emphasis on Western double standards (fascination with Tibet and support for exiled Tibetan groups), the final version adopts a more balanced approach, providing much additional data and delving into the details of the "social crisis" in Tibet.

\section{北京市、民政 局 收缴物品清单}

京民执数字 [2009]管 1 号

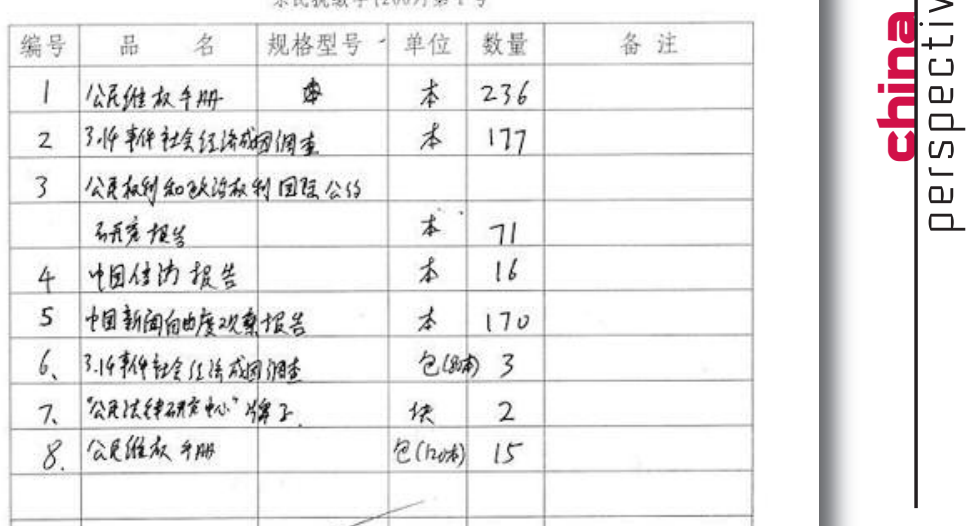

Neither Wang Hui nor the Gongmeng researchers-and even less the present reviewer-purport to be experts on Tibet; tibetologists will no doubt have much to add and to criticise in the writings discussed, and in the present article. However, these two publications by important actors in the internal debate in China-critical intellectuals within the academic system and non-governmental civil rights groups-are worthy of interest in their own right, in that they demonstrate the urgency of the challenges posed by the Tibetan deadlock to Chinese intellectuals and, despite the lack of public discussion on ethnic minorities acknowledged by Wang Hui (revised version, p. 47, n. 93), attest to the possibility for debate within China on the question of Tibet and government policy in Tibet. For this reason at least, it seemed worthwhile to discuss them. Both papers, in different ways, also use the Tibetan revolts to address more general questions of modernisation and China's present attitude to it, as well as Chinese nationalism and policies towards ethnic minorities in China. The "West" looms large in the background, especially in Wang Hui's analysis, but also more generally as a force promoting "modernity" in other areas of the world. Wang Hui's paper is organised into sections discussing Western Orientalism; the question of the nation-state and the Chinese political system (resting on the 
principle of duoyuan yiti, or "unity in diversity"); and the "post-revolutionary," "depoliticised" environment in which the "Tibet problem" began to fester, in his opinion. The Gongmeng report also investigates the question of "modernisation" in the post-1979 era and the structures of governance, and ends with two sections on the government's "errors" in handling the revolts and the challenges faced by Tibetan culture and religion today.

\section{The "Western" nation-state and colonialism}

Wang Hui's paper opens with a long section on "Orientalism," i.e., how Western understanding and mythification of Tibet, as well as colonialism, has distorted the nature of the Tibetan problem. The expanded version distinguishes between "two types" of Orientalism, positive and negative. Wang Hui quotes a series of examples to prove Western obsession with Tibet: CIA involvement in Tibet in the 1950s (quoting Melvyn Goldstein and Tom Grunfeld), the presence of Western missionaries, the widespread perception that Tibet is a peaceful country, the Enlightenment critique of Tibetan "superstition" (Hegel) and, in reaction, the esoteric nineteenth century mystic school known as "theosophy" founded by Helena Blavatsky (1831-1891). A bizarre conflation occurs at this point: Wang Hui analyses Blavatsky's fascination with Tibet, which she falsely claimed to have visited before converting to Buddhism in Sri Lanka; he then adds that the theosophy movement under Blavatsky developed a racialist theory of four original human species migrating out of Shambala, of which Tibetans are the last before the emergence of mankind. He adds that Blavatsky's racialism was instrumental in creating the image of a (racially) pure Tibet, uncontaminated by the evils of modern civilisation, in the eyes of many nineteenth and early twentieth century European intellectuals and, he suggests, exercised a decisive influence on Hitler and Nazism, for which Tibetans were the ancestors of the Aryans. He also recalls that Himmler sponsored the third expedition to Tibet in 1938 by the German ornithologist Ernst Schäfer, who had joined the SS in 1933. He highlights the importance of Tibet in Western pop culture, as embodied in James Hilton's novel Lost Horizon and the film Seven Years in Tibet, adapted from a book by Heinrich Harrer, a former Nazi and colleague of Schäfer's, who lived in Lhasa from 1946 to 1951, where he befriended the $14^{\text {th }}$ Dalai Lama as a teenager. Although the details do not purport to be more than anecdotal, they serve to pre- pare the argument that nationalism is a Western invention, and suggest a deeper affinity between nationalism, Nazism, and racialist worldviews: ${ }^{(5)}$

To the present day, Western society has still not shed this kind of Orientalist knowledge: those people who feel despair at the state of their own society and the contemporary world easily find spiritual consolation in the image of Tibet, but they never paid attention to the fact that their "theosophy" and their "extra-sensory techniques" not only distorted Tibet's reality and history, but could also hurt those Chinese people who were welcoming them with open arms. The Chinese did not know that they were faced with a bunch of Westerners deeply penetrated by several centuries of Orientalist knowledge, and that Tibet was precisely the artificially constructed Other inherent in them or in their Self. When Westerners realised the distance that separated the real Tibet from their creation, their bitterness erupted spontaneously-Tibet/the Orient was the prerequisite for their construction of their Self: now that this Other had suddenly freed itself from them, where could they find another one? Without a doubt, in this globalised world, Shambala has long disappeared. If they have lost faith in their own world, they will not find faith in any corner of it. (p. 176-177; revised p. 13)

In the revised version, these critiques are mitigated by a more substantial analysis of the Orientalism that has developed within Chinese society with regard to Tibet, suggested in the first paper through the case of Zhongdian in Yunnan Province, renamed as Shangri-La and transformed into a tourist destination.

It should be pointed out that one could just as easily argue that the West is and has been fascinated with China in an even more intense and long-lasting manner than with Tibet (including through the presence of countless missionaries). The feeling of "spiritual void" that Wang Hui discerns in Western society expresses itself at least as much in fascination with Chinese philosophy as with Tibetan Buddhism, and in addition is also strong in Chinese pop culture (films like Kekexili by Lu Chuan, 2004). It should furthermore be remembered that racialist discourse was widespread in Europe, as it was in

5. For a rebuttal of these views, see for example Isrun Engelhardt, "The Nazis of Tibet: A twentieth century myth," in Monica Esposito (ed.), Images of Tibet in the Nineteenth and Twentieth Centuries, Paris, Ecole française d'Extrême Orient, 2008. 
Asia, in the late nineteenth and the first half of the twentieth century (Wang Hui is certainly familiar with Zou Rong's Revolutionary Army in which the Manchus are described as a "furry and horned race" $\left.{ }^{(6)}\right)$; it seems somewhat anachronistic to project this worldview on the present-day, post-World War II and post-decolonisation Western world without mentioning that even within Europe, each country has different views of how ethnicity relates to nationality. This use of the word "Orientalism" goes beyond Said's indictment of Western academia (which Wang Hui has no major quarrel with); rather, he uses it to single out Western public opinion ${ }^{(7)}$ while at the same time recognising that a similarly mythical understanding of Tibet is pervasive in China-all in all, a somewhat impressionistic use of the concept.

Wang Hui's second main point is related to political structures and the historical relationship between Beijing and Lhasa. It opens with the assertion, "The problem of 'Tibetan independence' is entirely a product of modern colonialism; this point has been amply researched and backed up by many scholars" (p. 177). Although he initially quotes British colonial influence and Cold War politics, Wang Hui in fact analyses this question on a theoretical rather than an historical level, making the assertion that Western "imperialism" brought with it and introduced to Asia Western conceptions of sovereignty based exclusively on the nation-state. Wang Hui has previously made this point in several different contexts, making interesting criticisms of the empire/nation-state dichotomy and arguing that China's "modernisation" did not take place along these lines. ${ }^{(8)}$ In this instance he adds the concept of "trans-systemic society" (kua tixi shehui) to describe China, which remained within its imperial borders while developing into a nation-state (revised, p. 15).

This argument can only be made indirectly, as colonialism has a tense relationship with the nation-state model, which was invoked by independence movements against colonial powers during the decolonisation period, and Wang Hui does not entirely spell out how he views the connection between the two. Ernest Gellner's famous definition of nationalism as the "superposition of national and political borders" is quoted, but in a misleading way: this nationalism does not refer to colonialism in Gellner's book, but ratherone might almost say on the contrary-to the nationalism that emerged in continental Europe and was primarily directed against supra-national empires very similar to the Qing empire. ${ }^{(9)}$ Asian reality, Wang Hui concludes, was in any case much more complex, with relations between entities such as "allegiance" (chen shu) or "tribute" (chao gong). In the revised paper, providing considerable amounts of historical data, he puts forth the argument that the British policy of "unequal treaties" was designed to destroy these traditional relations between entities. ${ }^{(10)}$ This is nuanced by the description of how the Qing government used religion to control various border areas, and how nationalism was used by the Chinese revolutionary movement to oppose the Qing-although Wang Hui is careful to add that Chinese nationalism was mainly "anti-imperialist" and shed its antiManchu discourse immediately after 1911. While such complexities are historically undisputable, an obvious objection that is not addressed is that it was the government of the People's Republic of China (PRC) that ultimately tried to impose the "nation-state model" on Tibet in a much more immediate way than any British or American attempt to gain influence in Tibet, at the latest when the preservation of the Tibetan political system enshrined in the 17-Point Agreement of 1951 ended with the dissolution of the Tibetan government on 28 March 1959, and the creation of the Tibet Autonomous Region in 1965.

\section{The Chinese system of autonomous areas}

Wang Hui then sets out a detailed defence of what he believes was Zhou Enlai's uniquely Chinese administrative solution to the "nationality problem":

In my opinion, the view of China established in accordance with nationalist ideas cannot explain the unique reality of the autonomy system in China's ethnic

6. See also Frank Dikötter (ed.), with Barry Sautman, The Construction of Racial Identities in China and Japan, Hong Kong, Hong Kong University Press, 1997.

7. Wang Hui pinpoints popular support for the intervention of Western governments in Tibet. However, one might note that the most significant of these interventions, the one by the CIA, was neither motivated by nor justified in the name of the purity of Tibetan culture, but was a covert anti-communist operation that remained largely insulated from public opinion.

8. See Wang Hui, "The Liberation of the Object and the Interrogation of Modernity: Rethinking The Rise of Modern Chinese Thought," in Modern China, vol. 34, no. 1 (January 2008), pp. 114-140, in particular 123-133.

9. The Qing empire was not originally "Chinese" and, as Wang Hui himself points out, remained in many ways atypical (ibid. p. 132). Wang Hui designates this nationalism as one of the causes of the dislocation of the Soviet Union and Yugoslavia, but also, surprisingly, of the separation between India and Pakistan, which again places it in an uneasy connection with colonialism (it seems difficult to assert that India and Pakistan were two distinct nations forcibly united by British colonialism). In the earlier version of the paper the suggestion seems to be that Western colonial powers tried to organise colonized territories into "national" boundaries, or that they tried to govern supranational entities as one nationbut this would not apply to China, which was never colonised.

10. An interesting comparison might be with Korea, which was "encroached on" and then colonised at about the same time as the British set their sights on Tibet but, as it had been "truly" colonised, it never "reverted" to China despite the defeat of Japan in World War II. 
regions [minzu quyu zizhi zhidu]-this system is different from both the political principles of ethnic nationalism [zuyi minzu zhuyi de zhengzhi yuanze] and from the model of multi-national states [duoyuan minzu guojia de moxing]-such as, for example, federal republics that are constituted in accordance with the principle of national self-determination." ( $p .178)$

He quotes a 1957 speech by Zhou Enlai ("Minzu quyu zizhi you liyu minzu tuanjie he gongtong jinbu" or "The autonomy of ethnic regions benefits the unity between ethnic groups and common progress"), highlighting the difference between the Soviet situation that, because of the geographical separation of ethnic groups, was conducive to a federal solution, and the Chinese one, in which ethnic groups were inextricably intertwined from a geographical point of view. For this reason, Zhou rejected a federation of ethnically homogeneous entities for fear that the Han would migrate massively to non-ethnic areas. Wang adds that in 1949, the area of the present TAR was administered as three separate entities (one governed by the Dalai Lama, one by the Panchen Lama, and one by the Chamdo revolutionary liberation committee), which the Panchen Lama suggested retaining as three autonomous regions, and that it was in fact the Central Government that recognised the relatively homogeneous character of these Tibetan areas and decided to reunify them by creating the TAR, thereby making an exception to its own rule of accommodating the

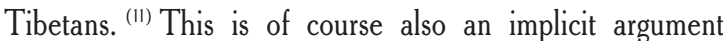
against an autonomous "Greater Tibet" within China.

The Maoist system of multi-ethnic autonomous regions was governed by two principles: the coexistence of ethnically different populations on the local level (down to the township or xiang level), and the will not to isolate ethnic minorities, in order to prevent their economic marginalisation (as in the case of native American reservations). In Wang Hui's view, the latter was decisive for Zhou Enlai. ${ }^{(12)} \mathrm{He}$ relates the policy of autonomy to political theories of important modern thinkers: Kang Youwei in his 1902 article "On self-government by citizens" (Gongmin zizhi pian) had already proposed that China would be best governed by granting autonomy to each township (xiang); the famous Republican-era historian Gu Jiegang had shown that the idea of a "Han nation" was a pure construction (in Central problems in writing Chinese history); Fei Xiaotong's "Theory of unity in diversity" (duoyuan yiti shuo) was meant to highlight that even each ethnic autonomous area would itself be ethnically diverse. In this respect, he argues, the Mao/Zhou solution of large-scale, ethnically integrated autonomous areas was a legacy of China's specific history; in the revised article he adds that it may be seen as "an inheritance of the empire, and a mix of nation-state and socialist values" (revised, p. 25). He goes so far as to underline that the officially recognised ethnic groups that emerged from the application and research process (shi bie) of the 1950s often had little if any consciousness of themselves as such collective entities. However, he underscores that the most important aspect of this system to him is that the unitary (yiti) aspect of the nation is purely political: it rests on adhesion (similar to Renan's idea of the nation as a daily plebiscite) and not on ethnic identities.

We can easily share Wang Hui's concern with a breakdown of China along ethnic lines. It will perhaps be more difficult to convince a European reader familiar with the ethnic mosaics of the Balkans or the Caucasus that a multiethnic reality on the local level is a uniquely Chinese phenomenon. $\mathrm{He}$ also seems to underestimate the influence of Stalin's nationality policy on the new PRC administration, in particular the mosaic system whereby each autonomous entity was in turn broken down into smaller autonomous entities-it is hard to argue, at least in the case of the Soviet Union, that this principle was not inspired by the will to divide and rule. ${ }^{(13)} \mathrm{He}$ does not distinguish between the present-day TAR and Xinjiang Uyghur Autonomous Region (XUAR), where Tibetans and Uyghurs occupied an overwhelming majority of the population in 1949, ${ }^{(14)}$ and other, ethnically more diverse autonomous regions and areas.

Here the Gongmeng report seems more daring: highlighting

11. This does not seem entirely factual; according to Melvyn Goldstein: "After the defeat of the Tibetan army in Chamdo in October 1950, the entire Chamdo region was reorganized under the administrative control of a liberation committee that was established on 19 October 1950 directly under the State Council in Beijing." (A History of modern Tibet vol. 2, p. 208, n. 5). Many thanks to Françoise Robin for pointing this out.

12. Wang Hui also highlights the influence exercised by non-Han communists within the CCP after the Long March passed through many ethnically diversified areas.

13. This view is put forth by Peking University professor Ma Rong: "The Chinese leaders, who were extremely inexperienced in administrative matters, had to seek support from the Soviet Union. They copied almost all the Soviet models in terms of administration, education, the economy, and military affairs. The government also followed the Soviet model by politicizing and institutionalizing the ethnic minorities in China." Ma Rong, "A New Perspective in Guiding Ethnic Relations in the Twenty-First Century: 'Depoliticization' of Ethnicity in China," Asian Ethnicity, vol. 8, No. 3 (October 2007), pp. 199-217; p. 213. Ma Rong also uses the term "politicisation" to refer to the process by which ethnic questions in the USSR and Maoist China were framed only in class terms as opposed to "culturalisation," rooted in traditional China, and dominant today in discussion of ethnic issues in the United States, for example-Wang Hui would probably see this as an example of "depoliticisation."

14. Uyghurs represented over $75 \%$ of the population in Xinjiang in 1949 , according to Graham Fuller and Jonathan Lipmann, "Islam in Xinjiang" in Frederick Starr, China's Muslim Borderland, Armonk, ME Sharpe, 2004, p. 323; Tibetans still occupy more than $90 \%$ of the population in the TAR today, according to official figures. 
the traditional Confucian attitude of jiaohua ("civilisation" of Barbarians), it notes that there are historical pre-conditions for a lack of legitimacy of Chinese presence, especially in U-Tsang (Weizang, central Tibet, roughly equivalent to the TAR), which, unlike Amdo, remained entirely "untouched" by the Chinese administrative system before the 1950s. Using an astute formulation to tread on very sensitive ground, the report concludes:

In the descriptions given by a large portion of the $U$ Tsang elite, modernization did not appear as a natural part of the modernization implemented in the entire country, but the result of compulsion from the political authorities on the central plains. Under the influence of the modern notion of "ethnic self-determination," part of the overseas $U-T$ sang elite regarded the Centre/UTsang relationship as one of mere "religious conferral," thus producing the illusion of a "state." (III.I)

The report further mentions the exclusion of populations in border regions from the status of "subjects" or "citizens" in Qing or Republican times, and the attitude of cultural superiority adopted by the representatives of Chinese power in Lhasa.

Wang Hui's insistence in the revised paper that the system of autonomous regions should not be traded for a simple system of "formal equality" is certainly worth endorsing (revised, p. 48); however, he entirely omits discussing the implications of the autonomy status itself and its implementation: are the provisions in articles 111-122 of the Chinese Constitution sufficient guarantees of autonomy, and have they been consistently implemented since 1949? ${ }^{(15)}$ This lack of critical analysis is somewhat surprising for someone who denounces the "formalistic" character of the modern legal system that is currently expanding in China (for example on p. 187). To quote but one example, how does Kang Youwei's (or Zhang Binglin's, or Liu Shipei's) ideal of government by small, autonomous, local structures relate to the "democratic centralism" enshrined in the CCP charter, which takes precedence over the Chinese constitution, including its provisions on ethnic autonomy? Finally, if the central government was so concerned with ethnic unity, why did it go about the hugely complex and costly process of identifying and certifying 55 "nationalities" and inscribing every citizen's ethnic identity in all official documents, using the word "minzu," the most common equivalent of the English word "nation" and similar words in other Western languages? Why can the Party Secretary of an Autonomous region never be a member of an ethnic minority (with the notable historic exception of Ulanhu in Inner Mongolia from 1947 until he was purged in 1966)? The Gongmeng report, by contrast, strongly recommends boosting the role of "ethnic cadres" in all areas of administration (III.2). It seems hard to believe Wang Hui's claim that it is Western colonial or Orientalist discourse that somehow imposed the concept of national or ethnic identity on the Chinese polity, whereas Zhou Enlai and the CCP were concerned with maintaining the multiethnic reality that existed in the Chinese tradition: much rather, his own argument seems to prove that it was the CCP, no doubt via the Soviet model, that imposed this "Western," nationality-based discourse onto a reality that, indeed, had little need or use for it.

In the Congmeng report, by contrast, as early as the foreword, the authors underscore the need to "evolve from being concerned with nationalities from the macro-perspective of building a nation-state, to being concerned with real problems such as the basic livelihoods of the masses in ethnic minority areas, the protection of their rights and interests, and the fostering of civic awareness and long-term social development" (Foreword). It is not the framework itself so much as its capacity to address the real challenges posed by non-Han areas that should take precedence. For example, regarding "equality," the report notes that "Tibetan ethnic awareness was actually inspired by the 3.14 incident. This was especially because after the incident and before the Olympics, a series of 'preventative measures' adopted by the government, such as Tibetans receiving 'special treatment' at airports and public spaces in the interior, made the Tibetan people, and in particular the youth, sense their 'differences' even more obviously" (II.3).

Furthermore, despite the large autonomy nominally devolved to local governments and their obligation to incorporate local culture and history into the education offered in these areas, the report highlights that all Tibetan textbooks are simple translations of Chinese ones, making no mention of Tibetan history or even cultural specificities such as the Tibetan calendar (II.4). The report therefore recommends a substantial revision of the autonomy status, stressing that local power has been monopolised by "deeprooted local power-elite networks" (pangen cuojie de bendi quanli jingying wangluo) bringing together officials, the new economic elite, and religious forces to form what the report calls a "new aristocracy" (xin gui jieceng). "Stability" has taken precedence over all other goals, and local elites

15. For such a discussion, see for example: China: Minority Exclusion, Marginalization and Rising Tensions, joint report Human Rights in China/Minorities Rights Group, 2007. 
can easily manipulate government policies to consolidate their own power. Here the report uses terminology that seems to be borrowed from Wang Lixiong's analysis of the "bureaucratic clique" that has taken over the governance of Tibet under the banner of "anti-separatism." (16) Too many cadres are chosen for political reasons and seriously lack any technical or administrative competence (III.2.[2]). Adopting Gongmeng's usual approach to legal problems, the report explicitly states that "with an attitude of "policies from above, countermeasures from below, local authorities contravene the Constitution and Regional Ethnic Autonomy Law, but at present the corresponding supervisory and accountability systems are still incomplete." (III.2.[2])

\section{"Modernisation": Social and cultural problems}

Echoing many Chinese commentators, Wang Hui wonders why, as the material situation of Tibetans has consistently improved (even during the Cultural Revolution, subsidies did not cease), the tensions in Tibet have worsened since 1980. His main thesis is that the Tibetan problem must be seen within the nationwide context: the unprecedented economic development that took place after 1980 has created growing disparities and conflicts within Chinese society, as mirrored in the exponentially increasing number of "mass incidents." Wang Hui cites three trends in reform-era China that are, in his view, related to the specific problems of Tibet: "depoliticisation" (the end of class-based politics), the revival of religion, and the marketisation of society (p. 183). He disagrees with an article published by Fred Halliday in Open Democracy comparing Tibetans and Palestinians as examples of "post-colonial sequestration": nations that missed the opportunity for independence because they did not obtain international recognition at a crucial moment. ${ }^{(17)}$ For him the "decolonisation" of Tibet has little relation with present-day problems: although the "democratic reforms" of 1959 entailed unnecessary violence, encountered some strong opposition, and led to excesses in areas such as religion, Wang Hui believes they were ultimately justified and benefited a majority of Tibetans because they established the principle of egalitarian politics and the separation of politics and religion:

From the 1950s to the 1980, Tibet underwent all sorts of crises, conflicts, and even destruction (for example the excessive policies of the "democratic reform" period and the eradication of religion and destruction of cultural heritage during the Cultural Revolution), but they had a completely different significance from the present-day "Tibet problem." (p. 184)

While this reviewer is not in disagreement with Wang Hui's argument, it should be pointed out, for the sake of the argument, that his "ultimate justification" of sometimes violent policies in the name of principles such as equality and secularism is subject to exactly the same criticism of "knowing better" as what he derides as Western Orientalism.

The current crisis, on the contrary, is rooted in the Reform era and linked by Wang Hui to his theory of "depoliticisation," which criticises the belief that government can be handled without significant political debate between opposing lines. ${ }^{(18)}$ In the revised paper, quoting Peking University sociologist Ma Rong's analyses of labour migration and ethnic inequalities in the TAR, ${ }^{(19)}$ as well as the Gongmeng report, Wang Hui emphasises several major problems that appeared after 1980. Recognising religion and atheism as "two roads to modernity," equally respectable and desirable, he highlights that government atheism is a major obstacle to the integration of Tibetan identity within Chinese identity. Quoting from the Gongmeng report, he notes that while land reform and its benefits served as a foundation for the legitimacy of the CCP among the older generation, the post-1980 reforms did not allow for a similar identification among younger generation; in this sense the 2008 revolt can be seen as a "crisis of post-socialism." The Gongmeng report also underscores that while the "modernisation movement held important political significance aimed at promoting a new political legitimacy" (I.I), enforcing the household contract responsibility system (chengbao), and allowing non-Tibetans to start their own businesses in Tibetan areas (I.1.[2]), its results, in terms of legitimacy, were not as good as expected: "The core of poli-

16. See the translated extract from Wang Lixiong's "Roadmap of Tibetan independence" in the present issue, and the full translation to be published as: Wang Lixiong, The Struggle for Tibet, London, Verso, 2009.

17. See: F. Halliday, "Tibet, Palestine and the politics of failure," 13 May 2008 http://www.opendemocracy.net/ article/tibet-palestine-and-the-politics-of-failure (12 July 2009).

18. While this is certainly a defendable opinion, in particular as applied to debates in the 1920s and 1930s, this reviewer does not share Wang Hui's positive evaluation of Mao's use of a "highly subjective concept of class" to "stimulate renewal of the Party's political culture" in the 1960-1966 period, after Mao had broken away from Moscow, and before the Cultural Revolution degenerated into factional "bureaucratisation" (and therefore depoliticisation). See Wang Hui, "Depoliticized politics, from East to West," New Left Review, no. 41 (Sept.-0ct. 2006), pp. 29-45, in particular pp. 36-37; Wang Hui, "Politique de dépolitisation et caractère public des medias de masse," Extrême-Orient, ExtrêmeOccident, no. 31 (2009); Wang Hui, Qu zhengzhi hua de zhengzhi. Duan 20 shiji de zhongjie yu 90 niandai (Depoliticized politics: A conclusion to the short twentieth century and the 1990s), Beijing, Sanlian, 2008.

19. See also note 13 above. 
viduals, but also weak groups-ethnic minorities, women, or migrants-are granted equal rights. This problem of reconciling equality and difference has not found satisfactory solutions in Western societies in which minority groups use "identity politics" to obtain "recognition" of their differences, thereby fracturing (fenlie) society. A real "politics of dignity" (Taylor) implies the equal expression of different cultures within the public sphere, as well as respect for diverse opinions within each ethnic group. Therefore, "the 'Han/Tibetan conflict' framework must be done away with, and a new politics of equality must be formulated, a more inclusive public space must be created, and, under new historical circumstances, the voices of ordinary people must be given a substantial chance to express themselves within this public space" (p. 188). This is certainly a praiseworthy objective and one that the Chinese government often impedes, not only in Tibet, but in many other parts of China, by controlling the press and local NGOs. ${ }^{(21)}$

For all these reasons, the Tibetan problem is a complex refraction of the challenges that face Chinese society as a whole. Toning down-though not erasing completely-his earlier denunciation of Western attacks on China (he uses fan Zhongguo rather than fan $H u$ in the final version, implying that Western public opinion was critical of the Chinese government rather than of the Chinese people), he also notes: "When attacking Western public opinion, the Chinese media never focused on the deep crisis in Tibetan society; the whole of society did not make use of this turning point to reflect on and rethink the connection between the logic of development in contemporary Chinese society and the Tibetan crisis" (revised, p. 48).

Wang Hui takes care to draw a line between himself and certain "New Left" viewpoints: "It must be explained that my discussion of a crisis in a situation of "depoliticisation' does not stem from nostalgia for the socialist era; it is meant to point out an often overlooked aspect: the Tibetan crisis is part of the general post-socialist crisis of the whole of China" (revised, p. 40). However, he continues to endorse the appearance of a "patriotic student movement," which has "burst onto the screens of the stultified official Chinese media," finally providing a true image of the "unofficial" (minjian) China by defending the Olympic torch relay. This movement implicitly exemplifies the "repoliticisation" that is his favoured solution to the Tibetan problem, as opposed to a "depoliticised" developmentalism promoted by the government (and the West). While taking care to state that student demonstrators may have had various motivations, he still links this movement to a universal symbol (the Olympic flame), and understands it as an opposition to Western hegemony (that deprived Beijing of the Olympics through "political manoeuvring" in 1993), and an endorsement of equality and inclusiveness in a multicultural society. However, he no longer refers to 1919, 1936, and 1989, or to the movement's difference from "European nationalism, especially the type of imperialism based on racist views" (p. 189 (22)).

For the Gongmeng report, on the other hand, the solutions are to be found in more pragmatic measures. Pointing out that, in the process of modernisation, "the systems in advanced countries should not be blindly copied," the report advocates utilising Tibetan Buddhism, which "not only should not be regarded as an obstacle to modernisation, but should actually be regarded as a reliable traditional resource for providing a functional basis for promoting the process of modernization in Tibetan areas." Noting that "religion can go fully hand in hand with modernisation," it criticises the government's, and especially local officials', continued distrust of religion (V), as exemplified by the unreasonable retaliation against monks after the March revolts (IV).

In conclusion, this reviewer finds much to agree with in Wang Hui's views on Tibet, especially in the revised version of the article. The multiethnic ideal that is, at least in name, enshrined in the Chinese constitution deserves to be upheld. It is more difficult to endorse his indictment of the "European" ideology of nationalism and the heritage of colonialism as causes for the radicalisation of Tibetans, ${ }^{(23)}$ ignoring the role of the Chinese state in legitimising the discourse on ethnic divisions. This critique seems all the more anachronistic at a time when the slow institutionalisation of the EU has, despite its shortcomings, called into question the exclusiveness of the nationstate framework, both by granting substantial autonomy to regional sub-divisions and by accepting the overarching framework of the Union (in particular the European Charter of Fundamental Rights, enforced by the European Court of Justice, as a last resort in legal matters, with binding force for all member states), in an echo of Europe's century-old dialectic history of fragmentation and reunification, not unlike China's. However, his plea for a "politics of dignity" rather

21. Wang Hui often uses Habermas's notion of "public space" and "publicness" (Öffentlichkeit or gonggongxing), whose relationship with Carl Schmitt's "politicisation" can only remain uneasy.

22. This assertion echoes an interview given to the Economic Herald two days before Wang Hui by Hong Kong University researcher Gan Yang, who similarly describes the torch protests as the birth of a new cosmopolitanism. See: "Ziqiang, zili, zixin, ziyou de Zhongguo" (A self-strengthening, self-sustaining, self-confident and free China), Ershiyi shiji jingji baodao, 26 April 2008.

23. Wang Hui quotes the example of how funding by Western NGOs encourages Tibetans to underscore their ethnic identity. 
than formal equality through further marketisation in minority areas is also an important statement, and it is worth reflecting on his arguments in favour of the autonomy system as the only possible framework for such a policy.

The analysis of dissatisfaction among Tibetans, its connection with the growing inequalities all over China, the expression of this dissatisfaction in "mass incidents" directed at corrupt or incompetent officials, and the resistance to certain forms of modernisation and secularism, are all convincing. Wang Hui's singling out, in his revised paper, of the specific form taken by these problems in Tibetan areas-the link between modernisation and Hanisation, the disempowerment of Tibetans in their own cities-is welcome, and underscores the importance of the findings in the Gongmeng report, which are quite impressive in their wide-ranging and systemic nature, especially concerning the importance of religion, the role of the local bureaucracy, and the formation of a new "aristocracy" in Tibet. It is important to note that all these points are analysed and publicised by Chinese researchers working within Chinese institutions. Even more noteworthy is the fact that both analyses accept that the legitimacy of the administration of Tibet (at least of the TAR) is not a given, or an incontestable legacy of history; much rather they argue that Maoist collectivization and redistribution policies provided Beijing with legitimacy in the eyes of Tibetan public opinion, and that this legitimacy has, since then, been severely eroded, and must be reconquered.

It is certainly to be hoped that Wang Hui's call for a truly free and inclusive public space can bring together Chinese and Tibetan critical voices, although one cannot help wondering, in this connection, whether the idealistic Chinese youth extolled at the end of the article might not find a cause more likely to be shared by their Tibetan counterparts in defending this public sphere and its accessibility to all rather than (albeit universal) symbols such as the Olympic flame. This call for diverse voices is substantiated by references to the Gongmeng report, Ma Rong's research, and also to several (unnamed) Tibetan friends and colleagues. Interestingly, Wang Hui does not mention Wang Lixiong or the signatories of the "Twelve proposals" to deal with the situation in Tibet ${ }^{(24)}$; when calling for diverse voices among Tibetan intellectuals to be heard, he also does not mention that many of these voices can express themselves only in Tibetan. However, these initiatives and debates attest to both the possibility and the crucial importance of an informed and dispassionate discussion on Tibet within China, as well as between Chinese, Tibetan and Western analysts. Tibetans and Tibetologists may not all agree with their strong socio-economic bend or their unwillingness to discuss alternative solutions to Beijing rule in Lhasa; however there remains much common ground for discussion, even in areas like religion and cultural rights.

As highlighted in the recommendations of the Gongmeng report, the question of modernity remains at the centre of the discussion. Wang Hui ties his observations to the existence of an "other" modernity, which he implies was sporadically embodied in the multi-ethnic, anti-nation-State, noncapitalist "Chinese" path that unfolded over the last century, including during at least some of the last 60 years in the PRC; ${ }^{(25)}$ it is certainly no less legitimate than the developmentalist, bureaucratic, nation-state centred path that has dominated in Europe. The crisis of the latter in recent years in China is well-documented, especially in its environmental and bureaucratic consequences. Nonetheless, it remains a little paradoxical that Wang Hui, who upholds the specificity of "Chinese modernity" and also, in his revised paper, of a Tibetan modernity characterised by a special relationship with religion, does not ask to what extent the present political institutions within the PRC allow Tibetans to make their own choices on this subject. While the conclusions of the Gongmeng report and Wang Hui's revised paper share many commonalities, the report's recommendation no. 7 deserves to be particularly emphasised:

Promote rule of law in governance processes in Tibetan areas. Urge the introduction of laws and regulations as represented by ordinances in the TAR and other autonomous areas, to change the current status quo of a lack of lower laws since the promulgation of the Regional Ethnic Autonomy Law. Regulate the ownership rights and disposal rights of key natural resources. Encourage participation by experts in advising and discussing all aspects of policy in Tibetan areas. (VI)

"Repoliticisation" cannot take place without institutionshere the lack of a bridge between a Habermassian public space and a Schmittian oppositional politics becomes particularly acute-and it is well worth reflecting on which institutions would serve the purpose most adequately. •

24. See Wang Lixiong et al., "Twelve Suggestions for Dealing with the Tibetan Situation, by Some Chinese Intellectuals," The New York Review of Books, Vol. 55, No. 8, 15 May 2008 (See http://www.nybooks.com/ articles/21379).

25. See note 18 above. This is of course debatable, as many proponents of "Chinese modernity" such as Zhang Binglin, or of Asian modernity, such as Takeuchi Yoshimi, were strongly opposed to the Chinese Communist Party's policy. 